\title{
Affectivity and the distinction between minimal and narrative self
}

\author{
Anna Bortolan ${ }^{1}$ (D) \\ Published online: 30 November 2019 \\ (C) The Author(s) 2019
}

\begin{abstract}
In the contemporary phenomenological literature it has been argued that it is possible to distinguish between two forms of selfhood: the "minimal" and "narrative" self. This paper discusses a claim which is central to this account, namely that the minimal and narrative self complement each other but are fundamentally distinct dimensions. In particular, I challenge the idea that while the presence of a minimal self is a condition of possibility for the emergence of a narrative self, the dynamics which characterise narrative selfhood do not have a structuring effect on minimal self-experience. I do so by drawing on both classical and contemporary phenomenological literature to show that at least certain forms of affective experience are complex phenomena in which minimal and narrative forms of selfhood are deeply entwined. More specifically, I claim that, due to their evaluative character, intentional and non-intentional affective states convey a pre-reflective experience of constitutive aspects of the narrative self. This enables me to argue that minimal and narrative selfhood are phenomenologically inextricable.
\end{abstract}

Keywords Affectivity $\cdot$ Minimal self $\cdot$ Narrative self $\cdot$ Self-consciousness · Phenomenology $\cdot$ Emotions $\cdot$ Feelings

\section{Introduction}

The contemporary debate on the nature of selfhood is characterised by the presence of a significant number of different notions of what a self is (Gallagher and Zahavi 2012: 219-220; Strawson 1999: 100; Zahavi 2008: 103), and it has been argued that at least some of these notions can be combined in a view of the self as a complex phenomenon. In particular, those among contemporary scholars who have investigated the self from a phenomenological point of view have recognised multidimensionality as a fundamental character of selfhood (Zahavi 2010). From

Anna Bortolan

anna.bortolan@abdn.ac.uk

1 School of Divinity, History and Philosophy, University of Aberdeen, Aberdeen, UK 
this perspective, elaborating on the insights provided by classical phenomenology, hermeneutics, and the cognitive sciences, Gallagher and Zahavi have identified two specific forms of selfhood: the "minimal self" and the "narrative self" (Gallagher 2000; Gallagher and Zahavi 2012; Zahavi 2007, 2008, 2010, 2014).

The minimal self is conceived in this context as a sense of self intrinsic to any phenomenally conscious state (Gallagher and Zahavi 2012; Zahavi 2014). According to this position, it is impossible to undergo any sort of experience without being simultaneously aware that the experience belongs to us, as there is a "sense of mineness," a primitive form of self-reference, inherent to any form of consciousness. The self at issue here is not given as an object, but rather as a subject of experience, and the notion of "pre-reflective self-consciousness," through which this experiential structure is referred to, aims to highlight this feature. Within this framework, it is also argued that the presence of a minimal self is independent of the possession of linguistic and conceptual abilities.

The narrative self, on the other hand, is viewed as a self which possesses an "individual identity" (Gallagher 2000: 18) and history, and is constituted through the engagement in a variety of personal and interpersonal forms of narrative activity. More specifically, it is suggested that cardinal to the narrative self is the ability to reflectively endorse certain experiences and values, and to integrate them in a coherent self-conception (cf. Gallagher 2000; Gallagher and Zahavi 2012; Zahavi 2007).

As far as the relationship between the two forms of selfhood is concerned, this account maintains that the minimal and the narrative self are complementary but distinct facets of the self. The presence of a minimal level of self-awareness is considered as a condition of possibility for the emergence of a narrative self. The latter, in other terms, is founded on the former and, although in ordinary experience they are usually integrated, it is implied that in some serious cases of erosion of narrative selfhood - for example in the most advanced stages of Alzheimer's diseaseonly the minimal self could still be present (Gallagher and Zahavi 2012: 231; Zahavi 2010: 5).

In this paper I aim to challenge this position through a phenomenological analysis of the relationship between affective experience and minimal and narrative self. While affectivity has been extensively investigated in both classical and contemporary phenomenology, this dimension of experience does not figure prominently in phenomenological debates on the nature of the self. In this study I suggest that bringing the two lines of enquiry into a closer dialogue can be beneficial. In particular, I show that the account of the relationship between minimal and narrative self widely held in contemporary phenomenology can be refined through the consideration of existing phenomenological accounts of affective experience.

To do so, after having reconstructed in Sect. 2. the account of selfhood here at issue, I move to consider what sort of relationship might exist between affects and the forms of self-consciousness which are thought to be integral to minimal and narrative self. I first draw attention to the fact that, in various phenomenologically oriented views, the feelings intrinsic to emotional experience are associated with a pre-reflective form of bodily self-consciousness, highlighting how this enables us to consider affectivity as a dimension of minimal selfhood. I then show that phenomenological accounts also suggest that affective experience is connected also to more 
complex forms of selfhood and self-consciousness, which can be considered akin to the narrative self. I argue that these accounts point towards the existence of forms of affective experience in which the minimal and narrative self are phenomenologically inextricable, thus challenging the idea that the structure of the minimal self is distinct from and impervious to the dynamics which take place at the level of the narrative self. As such, my analysis provides grounds to question the claim that minimal and narrative selfhood are asymmetrically related, and that disruptions of the latter may leave the former unaffected.

\section{Minimal and narrative selfhood in contemporary phenomenology}

\subsection{Minimal self}

The minimal self is essentially connected to conscious experience and self-consciousness. In line with classical phenomenological accounts, Gallagher and Zahavi suggest that integral to any phenomenally conscious state is a "first-personal presence" (Gallagher and Zahavi 2012: 56), namely that experiences are given immediately as one's own experiences without any inferential process being needed. Characteristic to the "what it is like" of every mental state would then be a "sense of mineness," that is the sense that the mental state belongs to oneself. As Zahavi explains:

When I (in non pathological standard cases) am aware of an occurrent pain, perception, or thought from the first-person perspective, the experience in question is given immediately, noninferentially and noncriterially as mine. If I feel hunger or see a sunrise, I cannot be in doubt or be mistaken about who the subject of that experience is, and it is nonsensical to ask whether I am sure that I am the one who feels the hunger. (Zahavi 2008: 124)

Gallagher and Zahavi attribute to this form of self-experience a "pre-reflective" character. Such notion of pre-reflectivity has various aspects, however, key to this account is the idea that pre-reflective self-awareness has both a "non-observational" and "non-objectifying" nature (2012: 52). As Gallagher and Zahavi explain, on the one hand, this experience is "non-observational" because it does not depend on any kind of introspective attitude taken by the subject towards the experience itself. On the other, it is "non-objectifying" because through it the self is not given as an object, but rather as the subject of a conscious state.

Minimal selfhood is considered to be fundamentally connected with pre-reflective self-consciousness. Indeed, by drawing attention to the "self-referentiality" characteristic of any form of phenomenal consciousness, Gallagher and Zahavi claim that selfhood is dependent on the structure of experience and, in particular, self-experience. As they clarify:

[...] the claim is that the (minimal or core) self possesses experiential reality, and is in fact identified with the first-personal character of the experien- 
tial phenomena. At its most primitive, self-experience is simply a question of

being pre-reflectively aware of one's own consciousness. (2012: 226)

From this perspective, the notions of pre-reflective self-consciousness and minimal selfhood appear to overlap, as the minimal self is described as "a consciousness of oneself as an immediate subject of experience" (Gallagher 2000: 15). In other words, the idea is that the first-personal givenness which characterises our experiential life is constitutive of an experiential sense of self with which a basic form of selfhood is identified. It is also important to note, however, that the term "pre-reflective" is also considered to mean "pre-conceptual" and "prelinguistic," as the self-experience integral to phenomenal consciousness is taken to be independent of the possession of a self-concept and the ability to articulate it linguistically (Gallagher and Zahavi 2012: 227-228).

The minimal self is also, importantly, considered to be both embodied and embedded in the environment (Gallagher and Zahavi 2012: 227; Zahavi 2010), an idea which is consonant with phenomenological accounts of intentional and, in particular, perceptual experience. Drawing attention to the fact that originally the body is not given as one among other objects, but rather as that in virtue of which other objects can be perceived, phenomenologists have provided an account of the body as it is subjectively lived (Husserl 1989; Merleau-Ponty 1962). From this perspective, as remarked by Legrand (2011), in order for a world to appear to an experiencing subject, the experiencing subject itself must be in the world, and, because of this reason, it must be embodied (208-209). This kind of bodily experience has a non-objectifying and non-observational character and can thus be considered to be a form of pre-reflective self-consciousness. Awareness of the body as a subject, in other terms, needs to be an integral aspect of minimal selfhood, an idea which appears to be corroborated by Gallagher and Zahavi's (2012) characterisation not only of the "sense of ownership," but also of the "sense of agency" as dimensions of pre-reflective self-experience.

\subsection{Narrative self}

Gallagher and Zahavi acknowledge that the concept of minimal self does not exhaust our ideas regarding the nature of selfhood. When we think of a self, they claim, we think of something more than a mere subject of experience (Gallagher 2000: 18; Zahavi 2008: 107). Rather, what we often have in mind is a richer notion, which, in their opinion, is best accounted for through the concept of narrative self.

A key feature of the narrative view they put forward is the acknowledgement of the historical structure of selfhood, namely the idea that the self is not a static entity, but rather something that is constituted and evolves over time. Gallagher and Zahavi recognise that a fundamental aspect of this development consists in the endorsement of specific values, cares, and beliefs and suggest that this is the process at the origin of the narrative self's "individual identity" (Gallagher 2000: 18) or "personality" (Zahavi 2007: 193). In this context, the narrative self is considered as a self with a "story" and a "personal character," while the minimal self is associated only with a "formal kind of individuation" (Zahavi 2007; 2014) because it is viewed as unrelated to the events, decisions, and ideals which shape an individual life and allow to distinguish the self from others in a more substantial way. 
As they consider the notion of "personal identity" or "personality" to be central to the understanding of what a narrative self is, Gallagher and Zahavi suggest that it might be appropriate to use the term "self" to refer to the experiential subject of minimal selfhood, while the individual who is constituted through autobiographical narrativity can be referred to as "person." In their words:

One option is to distinguish between an experiential self and a narrative self [...]. Another option is to opt for a deeper terminological differentiation. When dealing with the experiential self, one might retain the term 'self' since we are dealing precisely with a primitive form of self-experience or self-referentiality. By contrast, it may be helpful to speak not of the self, but of the person as a narrative construction. After all, what is being addressed by a narrative account is the nature of my personal character or personality, a personality that evolves through time and is shaped by the values I endorse, my moral and intellectual convictions and decisions, and my actions. (Gallagher and Zahavi 2012: 228)

Gallagher and Zahavi, then, associate the narrative self with personhood and, as highlighted above, they suggest that individual history and the endorsement of certain values are fundamental features of this kind of self. This characterisation is adopted also by other phenomenologically oriented approaches which conceive of narrativity and personal identity as closely connected. Rosfort and Stanghellini (2009), for example, emphasise that personhood is dependent on the ability to take an "evaluative stance" (254) with regard to one's own experiences and to make decisions about what kind of person one wants to be. Being a person, in other terms, requires the capacity to exercise one's will in order to give a particular orientation to one's existence and this is explicitly contrasted with the structure of the minimal level of self-experience (2009: 254).

The emphasis posed on the role of evaluative position-taking also draws attention to the fact that narrative self-understanding has a reflective character (cf. Zahavi 2010, 2014). In contrast to the primitive, non-observational and non-objectifying nature of pre-reflective self-awareness, reflective self-consciousness is an explicit and objectifying awareness of the self. It is indeed observed that cardinal to the structure of reflection is the distinction between the "reflecting experience" and the object reflected upon (Gallagher and Zahavi 2012: 69) and, as such, any experience where the subject takes herself as an object is a form of reflective self-consciousness. The ability to engage in autobiographical story-telling presupposes the capacity to think about oneself and to take a stance towards the features of the self that are so conceived. Therefore, within the phenomenological account in question, reflectivity is also a condition of possibility for narrativity and personhood.

\subsection{The multidimensional account}

Zahavi $(2010 ; 2014)$ remarks that the distinction between minimal and narrative self should be comprised within a multidimensional account of selfhood. In his opinion, minimal and narrative self are aspects of the same phenomenon and not two separate 
entities and, as such, he suggests that we should speak of a "multifaceted self" rather than "a multiplicity of co-existing selves" (2010: 6). Minimal and narrative self are here characterised as complementary but distinct dimensions, and this becomes particularly clear when their relationship is taken into consideration.

In this regard, it is maintained that in order for a narrative self to emerge, a minimal level of selfhood should already be established. The minimal self, in other terms, is considered to be a condition of possibility for the emergence of a narrative self. Experiential selfhood, according to Gallagher and Zahavi, "must be regarded as a prelinguistic presupposition for any narrative practices," since, in their opinion, "experiences and actions must already be given as mine if I am to worry about how they hang together or make up a coherent life story" (2012: 227-228).

However, within this account the relationship between minimal and narrative self is asymmetrical, as "narrative personhood presupposes experiential selfhood (but not vice versa)" (2012: 228). In line with this idea, it is suggested that disruptions of minimal self-experience would negatively affect the structure of narrative self-understanding (cf. Gallagher 2007), but it is accepted that there might be circumstances in which the latter is disturbed and the former is unaffected, as it could be the case, for example, in the advanced stages of Alzheimer's disease (Gallagher and Zahavi 2012: 231; Zahavi 2010: 5).

Gallagher and Zahavi suggest that, even when narrative abilities are severely disrupted, the first-person perspective, and thus the primitive level of selfhood, could be intact (2012: 231). These might be extreme, exceptional cases; however, the existence of such a possibility, along with the acknowledgment that the relation of "presupposition" or dependency which holds between the minimal and narrative self is one-directional, highlights an important aspect of Gallagher and Zahavi's account, and one which has had a significant impact on its applications in other philosophical areas, for example in the field of philosophical psychopathology. 1

Gallagher and Zahavi's account thus depicts the minimal and narrative self as phenomena that are usually integrated. However, in so far as it admits of the possibility for the minimal self to exist without a narrative self and to be unaffected by disruptions of narrative self-understanding, this account also conceives of the two dimensions as distinct, an idea which, as I will highlight in the following section, can be challenged by taking into consideration the structure of a pervasive type of experience: affectivity.

\footnotetext{
${ }^{1}$ In accounting for the disturbances of the self characteristic of certain psychiatric disorders, various scholars have indeed differentiated between more and less serious impairments depending on whether the minimal or narrative level of selfhood is thought to be affected. In particular, studies in this area have often focused on a comparative phenomenology of schizophrenia and depression and, while the former has generally been conceived as involving disruptions of the minimal self, the latter has been considered as a disturbance of narrative self-understanding and, as such, as involving a less dramatic alteration of self-experience (cf. Parnas and Sass 2001; Radden 2013; Sass and Parnas 2003; Sass and Pienkos 2013a, b).
} 


\section{Affectivity and selfhood}

\subsection{Bodily feelings and pre-reflective self-consciousness}

Various scholars have investigated the relationship between affectivity and selfconsciousness from a phenomenological perspective. In this regard, particular attention has been given to the bodily feelings implicated in the experience of emotions and other affective states. In the following I will illustrate some of the insights into this topic put forward by contemporary scholars, showing how these accounts highlight the existence of a connection between affectivity and minimal selfhood.

Phenomenological accounts tend to converge on the recognition that bodily feelings are central to affective experience. In contrast to the idea-held by cognitive theories-that emotions can be identified with particular beliefs or judgments (cf. Tappolet 2000)—phenomenologists have argued that affective states differ from cognitive states because of their being essentially "felt" (De Monticelli 2003; Scheler 1973a; Slaby 2008). From this perspective, feelings are integral to the structure of emotions, and it is claimed that at least some of them are best accounted for as specific forms of bodily experience. But how is the body experienced through such feelings?

A response to this question in the contemporary literature is provided by Colombetti's analysis of the role of the different types of bodily feelings intrinsic to emotions. Colombetti observes that sometimes the bodily feelings associated with emotional experience have a prominent position in our experiential field, suggesting that these are the feelings on which the accounts of the bodily aspect of affectivity usually focus. When we experience these feelings, she notes, the body "comes into relief," it is, so to speak, "in the foreground" (2011: 295-296):

[...] in many emotion experiences, one's body somehow "stands out" from the field of awareness and engrosses one's mind-as when I perceive my heart beating very fast after ducking a viper suddenly spotted in the middle of the hiking trail, or when I feel a knot in my throat as I am to report the death of a loved one, or when I sense my stomach contracting as I walk by a patch of vomit on the pavement. (2011: 294)

However, according to Colombetti, the bodily feelings involved in emotional experience are not always as salient, and can rather be at the periphery of our experiential field. These feelings do not "stand out" (297) as foreground bodily feelings do, yet they are not invisible: they are experienced in a more "recessive" way (305), but still contribute to the phenomenology of the emotions they are part of. From this perspective, background bodily feelings are conceived as the means by which the contents of affective experience can be given. An illustration of this feature is provided by Colombetti through the analysis of the experience that can be undergone when travelling to the airport on a train that has been delayed. In this case, Colombetti argues, our focus is usually on the objects in the external world-for example the train's speed or the announcements given-but 
the experience has also an unpleasant feel to it, "a quality of urgency," which depends on the presence of certain background bodily feelings (2011: 297).

Colombetti claims that although background and foreground bodily feelings are different forms of bodily experience, the body is in both cases experienced as a subject and not as an object. In other terms, the distinction between background and foreground bodily feelings does not correspond to the one between pre-reflective and reflective self-consciousness. On the contrary, according to Colombetti, both types of feeling are forms of pre-reflective bodily experience. In her view, the affective body can thus have various degrees of experiential conspicuousness without losing its subjectivity. Both background and foreground bodily feelings are experiences of the body as a subject and they differ in virtue of possessing different degrees of "self-presentation or self-intimation" (2011: 305).

The idea that the bodily feelings associated with affective experience are forms of pre-reflective self-consciousness emerges also from other accounts of the relationship between affectivity and self-consciousness. Slaby (2008), for example, claims that the experience of the body integral to emotional feelings is to be comprised under the notion of "body schema" and maintains that this should be conceived not as an experience in which we focus on the body, but rather as an experience in which the body "functions as a vehicle of perception" (437).

Moreover, Slaby's work explicitly acknowledges the existence of a connection between affectivity and selfhood. According to this view, affective states have a "self-disclosive" role, as not only they enable us to experience particular aspects of the world, but integral to them is also always a particular experience of the self in relation to that world (Slaby and Stephan 2008; Slaby and Wüschner 2014). To be more precise, Slaby suggests that intrinsic to every affective experience is a "sense of ability" (2012), namely a sense of one's agentive potentialities in a particular situation. He calls this self-related dimension of affective experience "affective self-construal" and attributes to it a bodily character. In his opinion, this is indeed an "embodied, modifiable sense of "I can" and "I cannot"" (153) which is at the core of our being in the world. In addition, Slaby and Wüschner suggest that these forms of self-experience are given implicitly, prior to reflection, and as such, they claim that "[a]ffective self-construal constitutes a kind of 'minimal self'" (2014: 224).

The accounts of affective experience considered in this section do not focus on the distinction between minimal and narrative self, however, due to the emphasis they pose on pre-reflective forms of bodily consciousness, the insights they develop can be discussed also in relation to that distinction.

Colombetti's and Slaby's views corroborate the idea that affectivity is a cardinal aspect of the minimal self and the form of self-consciousness that defines it. As previously mentioned, an essential feature of the minimal self is that it is an embodied self of which we have a non-observational and non-objectifying awareness, and it is exactly this form of self-experience which is shown to be integral to emotional feelings. The bodily feelings intrinsic to affective experience are instances of prereflective self-consciousness: through these feelings, in other terms, the body is experienced not as an object, but rather in its subjectivity. As such, emotions appear 
to be a constitutive aspect of the pre-reflective experience we have of ourselves as bodily selves.

At this point, however, it is important to explore further the characteristics of the "affective minimal self" to the existence of which Slaby and Wüschner (2014) draw attention, in order to understand whether this is entirely within the remit of Gallagher and Zahavi's notion, or whether it is something that cannot be accommodated within their account. I will argue in the following that a phenomenological account of affective self-consciousness enables us to claim that the self of which we have a pre-reflective experience is not just a minimal self, but rather a self which possesses some of the characteristics that Gallagher and Zahavi attribute to the narrative self. As such, it will be possible to put into question the idea of there being a fundamental distinction and an asymmetrical relationship between minimal and narrative self. On the contrary, the two will appear to be essentially entwined, thus suggesting that alterations of one of these dimensions would also likely bring about alterations of the other.

\subsection{Affectivity and consciousness of the narrative self}

In order to understand how the narrative self is involved in affective experience, it is first of all important to look at the connection which exists between affectivity and evaluation. Some phenomenologists have argued that feelings of different kinds are fundamental to our ability to appraise objects, people, events, or states of affairs as possessing particular properties (cf. De Monticelli 2003; Scheler 1973a). For example, through fear we can experience something as threatening or dangerous, through indignation as unjust or offensive, through curiosity as interesting or stimulating. More specifically, at the core of some phenomenological accounts is the idea that affective experience is essential in order for us to be able to perceive evaluative properties of different kinds-for instance, ethical or aesthetic properties-and that these could not be adequately given if we were to rely on cognitive capacities only.

Furthermore, and of paramount importance for the topic of this study, both classical and contemporary phenomenological accounts highlight how the connection between affectivity and evaluation is central to personhood. According to Scheler (1973a, b) and De Monticelli (2003; 2006), for example, it is by undergoing affective experiences of different kinds that we can build an individual evaluative outlook on the world, and this is what is at the core of being a person. This is possible because the experience of different affective states enables us not only to perceive values, but also to rank them in order of importance. Scheler, for example, suggests that affective experience includes also emotional acts of "preferring" and "placing after," namely experiences through which we experience certain values as having a "higher" or "lower" importance than others (Scheler 1973a: 260). In addition, the affective states with which phenomenologists are concerned in this context are not only short-lived, occurrent responses-what in the contemporary literature is often referred to through the term "emotion"-but also long-lasting and dispositional states like "sentiments" (De Monticelli 2006). As such, affectivity is seen as 
involved not only in episodic perceptions of value, but also as integral to the capacity to keep experiencing and endorsing something as valuable in certain ways over time.

From this perspective, personal identity is anchored in the possession of a set of evaluative preferences which is hierarchically ordered (De Monticelli 2003: 81), a dimension which, due to the role played by affectivity in its constitution, Scheler calls "ordo amoris" (1973b). In this context, the person's evaluative order of priorities constitutes the framework which orientates her cognitive and practical life, determining the kind of things she is sensitive and responsive to. Our evaluative perspective, in other terms, radically shapes the way in which we perceive ourselves, others and the world, and it is because of this reason that it can be considered to be the cornerstone of personal identity. "Whoever has the ordo amoris of a man," claims Scheler, "has the man himself" (1973b: 100).

The account which emerges from this strand of phenomenological research does not entail that evaluation and personal identity are solely a matter of affective experience. In order for an evaluative and personal perspective to be constituted and maintained over time, also other cognitive and volitional processes should indeed be in place. For something to be a long-term value or concern, it is not enough to be the object of certain affective responses: also a set of consistent beliefs, judgements, desires, and actions should be present. As argued by Bennett Helm (2009), something which has import for us is "worthy of attention and action" and is thus the focus of patterns of coherent responses, affective and of other types.

The fact that affectivity is not by itself a sufficient condition for the constitution of an evaluative perspective and personal character has been recognised also by phenomenologists. ${ }^{3}$ However, in this context it has been emphasised that affective experience has a primary and irreplaceable role in enabling us to perceive something as valuable and to respond to it accordingly. ${ }^{4}$ What is experienced as having import needs to be upheld and acted on behalf of in various ways, but our first step into the evaluative domain, and our main anchoring in it, is affectively laden.

How are these ideas relevant to the understanding of the relationship between affective experience and minimal and narrative self? Scheler and De Monticelli are not explicitly concerned with the notion of narrativity, however these accounts show that affectivity is central to the constitution of personal identity which, as discussed earlier, is considered by Gallagher and Zahavi to be a fundamental dimension of the

\footnotetext{
2 According to Lachterman's translation, the Latin "ordo amoris" means "the order or ordering of love" (Scheler 1973b: 98).

3 Within this tradition personhood has indeed been associated with the ability to perform "acts" (cf. Scheler 1973a; Stein 2000), namely to take a position with regard to the objects of one's experience and the experience itself, and only some of these acts have an affective character.

4 This is the case also due to the motivational role of affective experience, namely the fact that affects incline us to behave in certain manners, thus being key to the ability to act on behalf of what we value.
} 
narrative self. The form of selfhood which is the focus of the narrative account is indeed one which possesses an "individual identity" (Gallagher 2000: 18) or "personal character" and central to the emergence of which is the endorsement of certain "values" and "intellectual convictions and decisions" (Zahavi 2007: 193). As such, Scheler's and De Monticelli's positions indirectly draw attention to the fact that affective experience is tightly related to dimensions of the self that are more complex than the ones identified with minimal selfhood.

The relevance of phenomenological accounts of affectivity for the understanding of the relationship between minimal and narrative self, however, fully comes to light when we consider how self-consciousness is conceived within these accounts. According to various phenomenological approaches, affective experience indeed not only constitutes, but also discloses personal character. In other terms, from this perspective, affectivity not only shapes our personality, but is also cardinal to the experience we have of ourselves as individual persons.

This idea can be traced back to the work of early phenomenologists (cf. Frechette 2013). For example, Scheler himself associates affective experience and a certain form of self-awareness. In his words:

All "feelings" possess an experiential relatedness to the ego (or to the person). This relatedness distinguishes them from other contents and functions (sensing, representing, etc.) and is in principle different from the relatedness that can accompany representation, willing, and thinking. [...] When I feel "something," e.g., some value, this felt thing is joined to me more intimately through this function than anything is through representation. (Scheler 1973a: 332)

This view is further developed in contemporary phenomenology. Slaby (2008), for example, emphasises that the "outward-directed" and the "self-directed aspects" of emotions should not be considered as separate. On the contrary, the two aspects are inextricable in the structure of affective intentionality: when experiencing an emotion, I perceive something as possessing a particular evaluative property by feeling myself affected in a particular way. In Slaby's words:

While afraid, you experience something as dangerous and at the same time 'you' feel vulnerable in the relevant respect. But your experience of the danger is not separate from, but rather consists in your feeling thus vulnerable. [...] Your 'minding' and something else's 'mattering' are constitutively interrelated - there cannot be one without the other. (2008: 438)

According to this position, through intentional affective states we experience ourselves as affected in different ways and a connection is thus established between affectivity and self-awareness. Slaby and Stephan claim that bodily feelings are central to this form of experience, and this makes it possible to wonder whether what is at issue here is primarily a form of bodily self-consciousness. Indeed, as they explain, "[t]he felt body is essentially the arena in which affective self-consciousness manifests itself” (Slaby and Stephan 2008: 509).

However, the self which, through intentional feelings, is experienced as being affected by certain evaluative properties is not only a bodily subject, but rather 
an individual who possesses a specific set of values, cares, and concerns, shaped through a personal history. There is a high variety of stimuli to which one may respond with fear-for example, the prospect of losing one's job, moving to another country, or having to make a phone call to an angry family member-and the diversity of our responses reveals something about what is important to us and our previous experiences, or, otherwise said, about who we are as persons and our story.

The connection between affective experience and personhood appears to be even more prominent if we consider certain forms of non-intentional affective states. Research in classical and contemporary phenomenology has indeed often drawn attention to the existence of a set of feelings which do not seem to be directed to any particular object, person, event, or state of affairs, but appear to play a distinct, and fundamental, role in our mental and practical life. This is the case, for instance, of Ratcliffe's notion of "existential feeling" (2005, 2008), which bears similarities to the Heideggerian concept of "mood" (Heidegger 1962). In the following I will provide a brief account of Ratcliffe's view, aiming to subsequently illustrate how existential feelings are connected to the "narrative self."

At the centre of Ratcliffe's account is the idea that some non-intentional affects play a cardinal role in structuring our experience by making it possible for things to matter to us in distinct ways. According to Ratcliffe, existential feelings are a set of bodily feelings which act as "presupposed spaces of experiential possibility" (2005: 45), namely they determine the range of intentional states that we can entertain (2010). Existential feelings do not have intentional objects: however, due to the way in which they shape our possibility space, they are attributed a "pre-intentional" (2010) rather than merely non-intentional structure.

In order to best understand what pre-intentionality amounts to, we can take as an example the feelings of hopelessness which, according to Ratcliffe, can sometimes acquire an existential character (2013). Ratcliffe draws a distinction between forms of hopelessness which have specific contents, and the lack or loss of the capacity to hope itself. The latter form of hopelessness is not directed to any particular possibility, but is rather to be identified with the felt, painful inability to hope for anything. This is what Ratcliffe considers to be a "loss of radical hope" and a particular form of existential feeling. In his opinion, this form of hopelessness is to be distinguished from the loss of all intentional hopes, as radical hope is what is presupposed by our ability to entertain hopes with specific contents.

It has been argued that not only intentional feelings, but also non-intentional affects like existential feelings have an evaluative dimension. For example, Slaby and Stephan claim that existential feelings "can be described as various forms of evaluative awareness of one's existential situation," that is they suggest that while intentional feelings give us a sense of how we are affected by particular objects or events, existential feelings provide a more general "sense of how things are going for oneself" (Slaby and Stephan 2008: 507).

The way in which affects like existential feelings are connected to the individual's evaluative perspective can be further clarified if we take into closer consideration their pre-intentional character. As mentioned above, pre-intentionality in this context has to do with the role played by existential feelings in shaping the range of 
intentional states that it is possible for us to entertain. I have highlighted elsewhere (Bortolan 2017a) that this dynamic applies also to the domain of evaluation, as we can experience and judge things as being valuable in certain ways in so far as these are compatible with our existential feelings.

In addition, in line with some of the other phenomenological accounts illustrated before, Slaby and Stephan (2008) also emphasise that existential feelings fundamentally contribute to the constitution of our personal identity and to the consciousness we have of it. As previously discussed, these feelings are considered to be the grounds of particular intentional states, behaviours and attitudes, thus radically modulating our relation with the world, and it is for this reason that they can be seen to express "what we are," our identity, at any particular time. As such, Slaby and Stephan conceive of existential feelings as being both constitutive of personhood and forms of self-consciousness: "[t]hese feelings are, besides being candidates for what makes up our identity as persons, peculiar forms of being conscious of ourselves" (2008: 512).

According to this perspective, integral to existential feelings is thus a form of self-awareness which involves bodily experience, but cannot be reduced to consciousness of the body. What Slaby and Stephan draw attention to is indeed the fact that it is the self as a person that is experienced through these feelings. ${ }^{6}$ In their words:

“[...] we claim that particularly existential background feelings contribute importantly to a person's self-understanding. These feelings, more than anything else, are the proximate manifestations of both what kind of person a person is and, simultaneously, what the person takes herself to be (how she experiences her own current state of existence and the actual condition of the relevant parts or aspects of the world she lives and acts in)." (Slaby and Stephan 2008: 512)

In Sect. 2. I showed that Gallagher and Zahavi's account of the self associates personhood with reflectivity and, in particular, narrativity. According to this account, personal identity is something that we constitute and become aware of by engaging in narrative self-understanding and thus depends on a form of selfhood and self-consciousness more complex than the minimal one.

Slaby and Stephan's account, however, seems to suggest that we can have a degree of awareness of the self as a person at the pre-reflective level. Indeed, the self-directed aspect of existential feelings is depicted as the means by which the experience of one's relationship with the world is realised, thus suggesting that what is in question here is an experience of the self as subject rather than object. The self which, through different forms of affect, experiences the world,

\footnotetext{
5 This is the case also due to the fact that, while existential feelings can be short-lived, they can also be long-lasting, and even persist for an entire life (Ratcliffe 2008: 55), thus contributing to the stability of self-consciousness and selfhood over time.

${ }^{6}$ A similar idea is expressed by Rosfort and Stanghellini in their characterisation of moods: "We can say that whereas affects point forward toward a specific object, moods point inward toward my being the person I am" (2009: 260).
} 
or aspects of it, as possessing specific evaluative qualities, is not a self which is given as an object among other objects. Rather this is the felt subjective pole of any evaluation, which is given in the first place in a non-objectifying and nonobservational manner. As such, Slaby and Stephan's account contribute to draw attention to the fact that at least certain affective states are to be conceived as forms of pre-reflective personal consciousness, and this is very relevant for the characterisation of the relationship between affectivity and minimal and narrative self.

The form of self-consciousness that Slaby and Stephan associate with affective experience has a pre-reflective, bodily character, and therefore their account corroborates the idea that affectivity is closely connected to minimal selfhood. However, this account also suggests that what is experienced through existential feelings is not only a bodily self, but also the self as a person. In other terms, on the basis of Slaby and Stephan's account it is possible to suggest that we can have a pre-reflective experience of aspects of the self that the account of selfhood put forward by Gallagher and Zahavi associates with the narrative self and, in so doing, to highlight the fact that narrative understanding is closely intertwined with minimal self-experience.

This idea emerges even more clearly from the way in which Slaby and Stephan (2008) characterise the relationship between affectivity and linguistic and conceptual abilities. Calling into question the view according to which felt experiences and higher cognitive processes are separate dimensions, they indeed emphasise that certain existential feelings are inseparable from complex forms of thought, as "even the most intellectual, most conceptually polished attitudes can enter directly into the way we feel ourselves" (2008: 513).

Slaby and Stephan reach this conclusion by considering affects such as "the feeling of being a true American" and "of being a "moral failure", (2008: 513). In these cases, there appears to be a distinctive affective experience, but one which is rooted in the mastery of certain linguistic expressions and concepts. This, I believe, means not just that some affects can only be experienced once a particular level of cognitive development has been achieved, but also that the affective experience itself can be shaped by engaging in linguistically and conceptually-laden cognitive processes.

In both philosophy and other disciplines attention has been drawn to the impact that linguistic and, in particular, narrative expression can have on affectivity, influencing for instance the degree to which emotions are perceived as being controllable, their distinct character, and temporal structure (cf. Angus and Greenberg 2011; Bortolan Forthcoming; Colombetti 2009). This can apply to both intentional, shortlived affects, and non-intentional affective orientations like existential feelings. Ratcliffe himself indeed argues that existential feelings and narratives can be inextricable, and claims that they are to "be regarded as distinctive aspects of experience, rather than separable components" (2016: 170). This suggests that not only affects impact on the dynamics which are integral to narrative selfhood in various ways, but also that they can in turn be moulded by such dynamics, thus further supporting the idea that the minimal and narrative self are deeply intertwined.

In the first section of this study I illustrated how, according to Gallagher and Zahavi, pre-reflective self-consciousness is a pre-linguistic and pre-conceptual 
awareness of an embodied self. On the basis of the characterisation of existential feelings and other affects subsequently illustrated, however, it can be argued that the notion of pre-reflective self-consciousness can be extended to include also other features. Indeed, a phenomenological exploration of affective experience shows that there can be a non-observational and non-objectifying consciousness of the self as a person, and such consciousness is in some cases dependent on the possession of specific linguistic and conceptual abilities.

Slaby and Stephan's account, for example, draws attention to the existence of affective forms of experience where both minimal and more complex forms of selfconsciousness are integrated. This approach is not explicitly concerned with narrativity; however, by taking into consideration the notion of consciousness of the self as a person, it points towards a phenomenon that has been argued to be integral to narrative self-understanding. As such, this account indirectly highlights the existence of experiences where minimal self-awareness and narrative understanding are inseparable.

Gallagher and Zahavi can conceive of the minimal self as distinct and independent from the narrative self because they associate each of these forms of selfhood with a distinct form of self-consciousness, and imply that we can only be aware of the narrative self through reflective experience. In other terms, while they emphasise that in every conscious experience we can be pre-reflectively conscious of the self as a subject, the self as a person appears to be, in their account, only accessible through reflection. However, as I have argued here, classical and contemporary phenomenological theories of affectivity make it possible to challenge this idea, as they show that key aspects of our "personality" are revealed to us pre-reflectively through intentional and non-intentional affective states.

This is not to deny that reflective self-consciousness plays a central role in narrative selfhood/personhood. Reflection is certainly cardinal to the processes through which we determine our evaluative outlook, build a self-concept, and negotiate it with others. However, the accounts of affectivity I have discussed highlight that we are aware of the core dimensions of narrative selfhood not only when we are thinking or deliberating about it, but pre-reflectively via the plurality of our affective experiences.

\section{Conclusions}

This paper has discussed one prominent feature of the phenomenological account of minimal and narrative self put forward by Gallagher and Zahavi by taking into consideration the way in which affectivity is related to both such notions of selfhood. In the first part of this study, I provided an overview of the key aspects of the account in question. I showed that the minimal self is conceived as an embodied subject of which we are pre-reflectively aware in every phenomenally conscious state. The narrative self, on the other hand, is conceived as a self with a specific history and personality, which is developed through a variety of personal and interpersonal story-telling activities. Narrative selfhood, as I highlighted, has also been characterised through the notion of "person," namely as a self who has a specific 
sets of values, cares, and concerns she identifies with, and which she constitutes and becomes conscious of through reflective activities. I then moved to illustrate how the relationship between minimal and narrative self has been characterised. I showed that minimal and narrative self are thought to be distinct aspects of a unitary phenomenon rather than separate entities, and to be connected in an asymmetrical way. It is indeed claimed that there can be no narrative self without minimal self, but not viceversa, as arguably there are cases in which the narrative self is disrupted or is no longer present, but the minimal self is intact.

The suggestion that the minimal self is independent from the narrative self in such a way has been discussed in the rest of the paper by drawing on phenomenological accounts of affective experience. I first drew attention to the fact that the bodily feelings which mark various affects have been viewed as conveying a prereflective consciousness of one's body, thus appearing to be integral to minimal selfhood. I then moved to show that both classical and contemporary phenomenological accounts of affectivity also point towards the existence of a relationship between affects and a form of self-consciousness and selfhood that is analogous to the narrative one. Drawing on these accounts, I maintained that the self disclosed by affective evaluations is a self with a specific set of concerns, cares, and values which are expressive of a distinct personality, a feature which is at the core of the notion of "self as a person" with which narrative selfhood is identified. Crucially, I maintained, this self is not experienced as an object, but rather as the subjective pole of felt evaluative relationships - that is, it is experienced pre-reflectively.

I then concluded by suggesting that Gallagher and Zahavi can conceive of the minimal self as independent from the narrative self because they associate the latter only with a reflective form of self-consciousness. The analysis carried out in this article, however, suggests that the narrative self, or self as a person, is something of which we also have pre-reflective awareness, thus being a dimension which, from a phenomenological perspective, it is not possible to disentangle from the minimal self. On this basis, it is to be expected that changes occurring at the level of the narrative self, by impacting on various aspects of affective experience, may have the potential to modify also pre-reflective self-consciousness. Changes in the form or contents of one's narratives, for instance, could influence some key features of one's pre-reflective sense of self. For example, disruptions in the unity and continuity of one's self-narratives may give rise to a fragmentation of one's self-experience, while a marked shift towards negative self-descriptions could hinder one's felt sense of bodily and agentive potentialities. ${ }^{7}$

Acknowledgements This paper stems from the research I conducted as an integral part of my $\mathrm{PhD}$ thesis. I am grateful to my PhD Supervisor, Matthew Ratcliffe, and to the academic community at Durham University for providing helpful advice during the period in which these ideas were developed. I have

\footnotetext{
7 An examination of how specific disturbances of narrative selfhood may affect minimal selfhood would exceed the scope of this paper. However, the research presented here provides support to the idea that the effects that alterations occurring at the level of the narrative self may have are more wide-ranging than often recognised in the phenomenological literature. In order to test this hypothesis, it appears promising to further explore the phenomenology of psychopathological conditions-such as depression-to which disturbances of both narrativity and affectivity have already been identified as central (cf. for example Bortolan (2017b) and Ratcliffe 2016).
} 
further elaborated and finalised this research in my position as an Irish Research Council Government of Ireland Postdoctoral Fellow (Project ID: GOIPD/2016/555), and I thus wish to thank the Council for their support at the time. This paper was presented at the conference "Personhood and Self-Consciousness" at the University of Manchester in July 2018 and I am grateful to the audience for stimulating conversations. My thanks go also to James Jardine, James Miller, and Alessandro Salice for their feedback, and to an anonymous reviewer.

Open Access This article is distributed under the terms of the Creative Commons Attribution 4.0 International License (http://creativecommons.org/licenses/by/4.0/), which permits unrestricted use, distribution, and reproduction in any medium, provided you give appropriate credit to the original author(s) and the source, provide a link to the Creative Commons license, and indicate if changes were made.

\section{References}

Angus L.E., and L.S. Greenberg. 2011. Working with Narrative in Emotion- Focused Therapy. Changing Stories, Healing Lives. Washington: American Psychological Association.

Bortolan, A. Forthcoming. Narratively Shaped Emotions: The Case of Borderline Personality Disorder. The Journal of Medicine and Philosophy.

Bortolan, A. 2017a. Affectivity and Moral Experience: An Extended Phenomenological Account. Phenomenology and the Cognitive Sciences 16(3): 471-490.

Bortolan, A. 2017b. Affectivity and Narrativity in Depression: A Phenomenological Study. Medicine, Health Care and Philosophy 20(1): 77-88.

Colombetti, G. 2009. What Language Does to Feelings. Journal of Consciousness Studies 16(9): 4-26.

Colombetti, G. 2011. Varieties of Pre-Reflective Self-Awareness: Foreground and Background Bodily Feelings in Emotion Experience. Inquiry 54(3): 293-313.

De Monticelli, R. 2003. L'Ordine del Cuore: Etica a Teoria del Sentire. Milan: Garzanti.

De Monticelli, R. 2006. The Feeling of Values. For a Phenomenological Theory of Affectivity. In Theories and Practice in Interaction Design, ed. S. Bagnara and G. Crampton Smith, 57-75. Mahwah: Lawrence Erlbaum Associates.

Frechette, G. 2013. Searching for the Self: Early Phenomenological Accounts of Self-Consciousness from Lotze to Scheler. International Journal of Philosophical Studies 21(5): 654-679.

Gallagher, S. 2007. Pathologies in Narrative Structures. Royal Institute of Philosophy Supplement 60: 203-224

Gallagher, S. 2000. Philosophical Conceptions of the Self: Implications for Cognitive Science. Trends in Cognitive Sciences 4(1): 14-21.

Gallagher, S., and D. Zahavi. 2012. The Phenomenological Mind, 2nd ed. New York: Routledge.

Heidegger, M. 1962. Being and Time. Translated by J. Macquarrie and E. Robinson. Oxford: Blackwell.

Helm, B.W. 2009. Love, Identification, and the Emotions. American Philosophical Quarterly 46(1): 39-59.

Husserl, E. 1989. Ideas Pertaining to a Pure Phenomenology and to a Phenomenological Philosophy. Second Book. Studies in the Phenomenology of Constitution. Translated by R. Rojcewicz and A. Schuwer. Dordrecht: Kluwer Academic Publishers.

Legrand, D. 2011. Phenomenological Dimensions of Bodily Self-Consciousness. In Oxford Handbook of the Self, ed. S. Gallagher, 204-227. Oxford: Oxford University Press.

Merleau-Ponty, M. 1962. Phenomenology of Perception. Translated by C. Smith. London: Routledge \& Kegan Paul.

Parnas, J., and L.A. Sass. 2001. Self, Solipsism, and Schizophrenic Delusions. Philosophy, Psychiatry, \& Psychology 8(2/3): 101-120.

Radden, J. 2013. The Self and Its Moods in Depression and Mania. Journal of Consciousness Studies 20(7-8): 80-102.

Ratcliffe, M. 2005. The Feeling of Being. Journal of Consciousness Studies 12(8-10): 43-60.

Ratcliffe, M. 2008. Feelings of Being: Phenomenology, Psychiatry and the Sense of Reality. Oxford: Oxford University Press.

Ratcliffe, M. 2010. Depression, Guilt and Emotional Depth. Inquiry 53(6): 602-626.

Ratcliffe, M. 2013. What is it to Lose Hope? Phenomenology and the Cognitive Sciences 12(4): 597-614. 
Ratcliffe, M. 2016. Existential Feeling and Narrative. In Funktionen des Lebendigen, ed. T. Breyer and O. Müller, 169-192. de Gruyter: Berlin.

Ricoeur, P. 1994. Oneself as Another. Translated by K. Blamey. Chicago and London: The University of Chicago Press.

Rosfort, R., and G. Stanghellini. 2009. The Person in Between Moods and Affects. Philosophy, Psychiatry, \& Pychology 16(3): 251-266.

Sass, L.A., and J. Parnas. 2003. Schizophrenia, Consciousness, and the Self. Schizophrenia Bulletin 29(3): 427-444.

Sass, L.A., and E. Pienkos. 2013a. Varieties of Self-Experience. A Comparative Phenomenology of Melancholia, Mania, and Schizophrenia. Part I. Journal of Consciousness Studies 20(7-8): 103-130.

Sass, L.A., and E. Pienkos. 2013b. Space, Time, and Atmosphere. A Comparative Phenomenology of Melancholia, Mania and Schizophrenia. Part II. Journal of Consciousness Studies 20(7-8): $131-152$.

Scheler, M. 1973a. Formalism in Ethics and Non-Formal Ethics of Values. Translated by M.S. Frings and R.L. Funk. Evanston: Northwestern University Press.

Scheler, M. 1973b. Ordo Amoris. In Selected Philosophical Essays, 98-135. Translated by D.R. Lachterman. Evanston: Northwestern University Press.

Slaby, J. 2008. Affective Intentionality and the Feeling Body. Phenomenology and the Cognitive Sciences 7(4): 429-444.

Slaby, J. 2012. Affective Self-Construal and the Sense of Ability. Emotion Review 4(2): 151-156.

Slaby, J., and A. Stephan. 2008. Affective Intentionality and Self-Consciousness. Consciousness and Cognition 17(2): 506-513.

Slaby, J., and P. Wüschner. 2014. Emotion and Agency. In Emotion and Value, ed. C. Todd and S. Roeser, 212-228. Oxford: Oxford University Press.

Stein E. 2000. Philosophy of Psychology and the Humanities. Translated by M. C. Baseheart and M. Sawicki. Washington: ICS Publications.

Strawson, G. 1999. The Self and the SESMET. Journal of Consciousness Studies 6(4): 99-135.

Tappolet, C. 2000. Emotions et Valeurs. Paris: Presses Universitaires de France.

Zahavi, D. 2007. Self and Other: The Limits of Narrative Understanding. Royal Institute of Philosophy Supplement 60: 179-202.

Zahavi, D. 2008. Subjectivity and Selfhood. Investigating the First-Person Perspective. Cambridge: MIT Press.

Zahavi, D. 2010. Minimal Self and Narrative Self. A Distinction in Need of Refinement. In The Embodied Self. Dimensions, Coherence and Disorders, ed. T. Fuchs, H. Sattel, and P. Heningsen, 3-11. Stuttgart: Schattauer.

Zahavi, D. 2014. Self and Other: Exploring Subjectivity, Empathy, and Shame. Oxford: Oxford University Press.

Publisher's Note Springer Nature remains neutral with regard to jurisdictional claims in published maps and institutional affiliations. 